\title{
Ionization of Acetic Acid in Electrolytic Solutions
}

\author{
A A R N E EL I L Ä \\ Chemical Institute, University of Helsinki, Helsinki, Finland
}

\begin{abstract}
A study of the salt solutions of weak electrolytes presents as good an opportu-

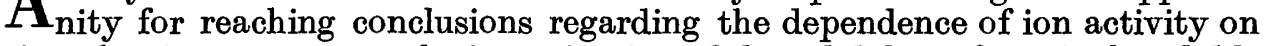
the other ions present as the investigation of the solubility of sparingly soluble salts. For this reason the writer has investigated the ionization of acetic acid in solutions of salts of alkali and alkaline earth metals. On the solutions of the former salts detailed assays have been published elsewhere ${ }^{\mathbf{1}}$, for which reason only a brief summary will be given here. Comments and further conclusions drawn from these have, however, been added.
\end{abstract}

\section{MEASUREMENTS PERFORMED ON SOLUTIONS OF SALTS OF ALKALI METALS}

The measurements were performed on solutions of 11 different salts and at two different ionic strengths. The conclusion was that the following equations are at least approximately true:

$\mathrm{p} K_{\mathrm{KCl}}-\mathrm{p} K_{\mathrm{NaCl}}=\mathrm{p} K_{\mathrm{KBr}}-\mathrm{p} K_{\mathrm{NaBr}}=\mathrm{p} K_{\mathrm{KNO}_{3}}-\mathrm{p} K_{\mathrm{NaNO}_{3}}=\mathrm{p} K_{\mathrm{KClO}_{4}}-\mathrm{p} K_{\mathrm{NaClO}_{4}}$ $\mathrm{p} K_{\mathrm{NaCl}}-\mathrm{p} K_{\mathrm{L}, \mathrm{iCl}}=\mathrm{p} K_{\mathrm{NaBr}}-\mathrm{p} K_{\mathrm{L}_{\mathrm{iBr}}}=\mathrm{p} K_{\mathrm{NaNO}_{3}}-\mathrm{p} K_{\mathrm{L}_{\mathrm{iNO}}}=\mathrm{p} K_{\mathrm{NaClO}_{4}}-\mathrm{p} K_{\mathrm{L}_{\mathrm{iClO}}}$ and

$\mathrm{p} K_{\mathrm{NaClO}}-\mathrm{p} K_{\mathrm{NaBr}}=\mathrm{p} K_{\mathrm{KClO}}-\mathrm{p} K_{\mathrm{KBr}}=\mathrm{p} K_{\mathrm{LiClO}_{4}}-\mathrm{p} K_{\mathrm{LiBr}}$

$\mathrm{p} K_{\mathrm{NaBr}}-\mathrm{p} K_{\mathrm{NaCl}}=\mathrm{p} K_{\mathrm{KBr}}-\mathrm{p} K_{\mathrm{KCl}}=\mathrm{p} K_{\mathrm{LiBr}}-\mathrm{p} K_{\mathrm{L}, \mathrm{iBr}}$

where $\mathrm{p} K=-\log K$.

The conformity presented by the equations can be expressed as follows: If, in solutions of equal ionic strength one ion of the electrolyte is substituted for another, this always causes the same change in the $\mathrm{p} K$ value for acetic acid, no matter what ion of the same charge the other remaining ion is. For this reason the $\mathrm{p} K$ value for acetic acid is an additive quantity separately dependent on each species of ion present.

The additivity phenomenon and Brønsted's theory

Brønsted ${ }^{2}$ was the first to note the additivity phenomenon when he investigated the solubility of sparingly soluble salts in electrolyte solutions. These observations made with dilute solutions led Brønsted to present his

Acta Chem. Scand. 8 (1954) No. 7 
theory of specific ionic interaction ${ }^{3}$. Applying Bronsted's theory to the ionization of acetic acid the influence of the activity of the unionized part on the equilibrium must also be taken into consideration. Larsson was the first to note that the logarithm of the activity coefficient of the unionized part of benzoic acid is additive in the same way as the $\mathrm{p} K$ shown above. From Sugden's ${ }^{5}$ measurements it can be proved that the same is also true for acetic acid. Applying Brønsted's theory to the case in question we have, for example,

$$
\mathrm{p} K_{\mathrm{KCl}}-\mathrm{p} K_{\mathrm{NaCl}}=\mathrm{p} f_{\mathrm{Ac}(\mathrm{K})}+\mathrm{p} f_{(\mathrm{K})}-\mathrm{p} f_{\mathrm{Ac}(\mathrm{Na})}-\mathrm{p} f_{(\mathrm{Na})}
$$

It can be observed that the difference indicated is independent of the anion of the salt added. In the equation Ac stands for the anion of acetic acid. This result is the same as that expressed by equations (1). Similarly it can be shown that equations (2) are also in conformity with Brønsted's theory. Consequently the observations reported here and those of Brensted are similar.

Harned ${ }^{6}$ has examined whether Brønsted's theory is applicable to concentrated solutions and found that it cannot be used for solutions stronger than $0.1 \mathrm{~m}$. Harned's results and the measurements presented for acetic acid are apparently in disagreement, which prompted us to more detailed examination.

Brønsted's theory can be represented by two postulates 7a:

1. Ions of unlike sign react differently upon one another, while ions of like sign react identically with one another.

2. Each ion has a characteristic "salting out effect" which acts upon all other in the solution.

The first postulate evidently corresponds to the concept of the structure of the solution given by Debye-Hückel's theory ${ }^{8}$. The same cannot be said about the second postulate. According to this each ion has a salting out and salting in effect upon another ion irrespective of the specific properties of the latter. Randall and Failey ${ }^{9}$, Harned and Owen ${ }^{7 b}$ and Long and McDevit 10 have collected data relating to the salting out and salting in effect upon neutral molecules. These data indicate that the specific properties of the particle upon which the effect is focussed must be taken into consideration. For this reason a corresponding correction should be made in the second postulate. Thus the activity coefficient of, for instance, hydrochloric acid in a solution of potassium chloride may be written as follows:

$$
f_{\mathrm{HCl}(\mathrm{KCl})}=f_{\mathrm{H}(\mathrm{K})} f_{\mathrm{H}(\mathrm{Cl})} f_{(\mathrm{H}, \mathrm{K})} f_{(\mathrm{H}, \mathrm{Cl})} f_{\mathrm{cl}(\mathrm{K})} f_{\mathrm{cl}(\mathrm{Cl})} f_{(\mathrm{Cl}, \mathrm{K})} f_{(\mathrm{Cl}, \mathrm{Cl})}
$$

where $f_{(\mathrm{H}, \mathrm{K})}, f_{(\mathrm{H}, \mathrm{Cl})}, f_{(\mathrm{Cl}, \mathrm{K})}$ and $f_{(\mathrm{Cl}, \mathrm{Cl})}$ represent the specific salting out and salting in terms obtained after applying the corrections to Brønsted's theory.

The following equations are obtained for the activity coefficients of potassium chloride in hydrochloric acid, hydrochloric acid in hydrochloric acid and potassium chloride in a solution of potassium chloride, respectively.

$$
\begin{aligned}
& f_{\mathrm{KC}(\mathrm{HCl})}=f_{\mathrm{K}(\mathrm{H})} f_{\mathrm{K}(\mathrm{Cl})} f_{(\mathrm{K}, \mathrm{H})} f_{(\mathrm{K}, \mathrm{cl})} f_{\mathrm{cl}(\mathrm{H})} f_{\mathrm{cl}(\mathrm{Cl})} f_{(\mathrm{Cl}, \mathrm{H})} f_{(\mathrm{Cl}, \mathrm{cl})} \\
& f_{\mathrm{HCl}(\mathrm{HCl})}=f_{\mathrm{H}(\mathrm{H})} f_{\mathrm{H}(\mathrm{Cl})} f_{(\mathrm{H}, \mathrm{H})} f_{(\mathrm{H}, \mathrm{Cl})} f_{\mathrm{cl}(\mathrm{H})} f_{\mathrm{cl}(\mathrm{Cl})} f_{(\mathrm{Cl}, \mathrm{H})} f_{(\mathrm{Cl}, \mathrm{Cl})} \\
& f_{\mathrm{KCl}(\mathrm{KCl})}=f_{\mathrm{K}(\mathrm{K})} f_{\mathrm{K}(\mathrm{Cl})} f_{(\mathrm{K}, \mathrm{K})} f_{(\mathrm{K}, \mathrm{Cl})} f_{\mathrm{cl}(\mathrm{K})} f_{\mathrm{cl}(\mathrm{Cl})} f_{(\mathrm{Cl}, \mathrm{K})} f_{(\mathrm{Cl}, \mathrm{Cl})}
\end{aligned}
$$

If the specific salting out and salting in terms are taken into consideration when an equation corresponding to equation (3) is derived, we have 
Fig. 1. Plots of 4 (equation 10) against ionic strength.

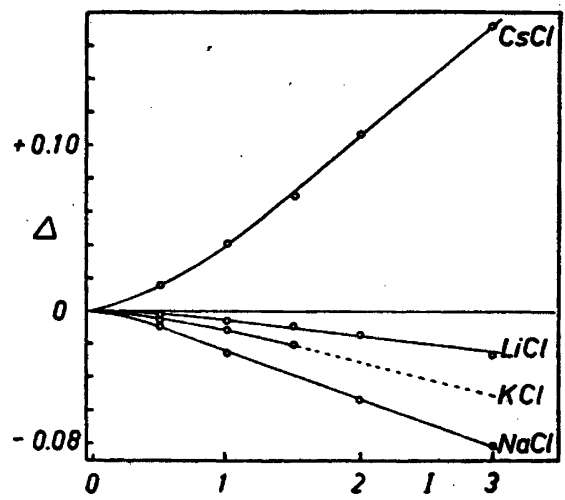

$$
\begin{gathered}
\mathrm{p} K_{\mathrm{KCl}-\mathrm{p}} K_{\mathrm{NaCl}}=\mathrm{p} f_{\mathrm{Ac}(\mathbf{K})}+\mathrm{p} f_{(\mathrm{Ac}, \mathbf{K})}+\mathrm{p} f_{(\mathrm{H}, \mathrm{K})}-\mathrm{p} f_{(\mathrm{HAc}, \mathbf{K})}-\mathrm{p} f_{\mathrm{Ac}(\mathrm{Na})}+\mathrm{p} f_{(\mathrm{Ac}, \mathrm{Na})} \\
+\mathrm{p} f_{(\mathrm{H}, \mathrm{Na})-\mathrm{p} f_{(\mathrm{HAc}, \mathrm{Na})}}
\end{gathered}
$$

which, like equation (3), indicates that the difference is dependent only on the cation of the electrolyte added.

From Brønsted's theory in its original form it follows directly that the following equations are valid:

$$
\log \frac{f_{\mathrm{AgCl}(\mathrm{HCl})}}{f_{\mathrm{AgCl}(\mathrm{MCl})}}=\log \frac{f_{\mathrm{RCl}(\mathrm{HCl})}}{f_{\mathrm{RC}(\mathrm{MCl})}}=\log \frac{f_{\mathrm{HCl}(\mathrm{HCl})}}{f_{\mathrm{HCl}(\mathrm{MCl})}}
$$

Harned and his co-workers ${ }^{11}$, using the potentiometric method, have investigated the activity coefficient of hydrochloric acid in aqueous solutions of alkali chlorides. On the basis of the values calculated from these measurements by Harned ${ }^{6}$, it is possible to ascertain whether equation (9) is valid for different cases. For this purpose equation (9) can be written in the following form

$$
\log \frac{f_{\mathrm{HCl}(\mathrm{HCl})}}{f_{\mathrm{HCl}(\mathrm{MCl})}}-\log \frac{f_{\mathrm{MCl}(\mathrm{HCl})}}{f_{\mathrm{MCl}(\mathrm{MCl})}}=\Delta
$$

where $\mathrm{MCl}$ denotes alkali chloride. In Fig. 1 the value of $\Delta$ is presented as a function of the ionic strength.

In all cases the value of $\Delta$ seems to approach zero as the ionic strength approaches zero. The requirement $\Delta=0$, which is prescribed by the original theory of Brønsted, is almost fulfilled in a 0.1 molal solution indicating that this theory is almost true when $0<I<0.1$. On approaching greater ionic strengths, however, the value of $\Delta$ increases or decreases rapidly from zero.

If, on the other hand, equations (4), (5), (6), and (7) are inserted in equation (10), it is observed that

$$
\log \frac{f_{(\mathbf{H}, \mathbf{H})}}{f_{(\mathbf{H}, \mathbf{M})}}-\log \frac{f_{(\mathbf{M}, \mathbf{H})}}{f_{(\mathbf{M}, \mathbf{M})}}=\Delta
$$

where $\triangle$ may have values differing from 0 , as in Fig. 1. According to Harned and Owen ${ }^{7 c}$ it can easily be shown that the theory modified as suggested no longer assumes that at constant ionic strength the osmotic coefficient in a 
solution of two electrolytes is a linear function of the concentration of both components. Owen and Cooke ${ }^{12}$ have been able to prove by isopiestic measurements that the osmotic coefficient does not increase linearly, but that the relation is of higher order.

\section{Debye-Hückel's formula and Brønsted's theory}

When Brønsted's original theory is applied to the ionization of acetic acid in a solution of potassium chloride, we get the equation:

$$
\mathrm{p} K_{\mathrm{KCl}}=\mathrm{p} K_{\mathrm{o}}-\mathrm{p} f_{\mathrm{H}(\mathrm{K})}-\mathrm{p} f_{\mathrm{H}(\mathrm{Cl})}-\mathrm{p} f_{\mathrm{Ac}(\mathrm{Cl})}-\mathrm{p} f_{\mathrm{Ac}(\mathrm{K})}-\mathrm{p} f_{(\mathrm{K})}-\mathrm{p} f_{(\mathrm{Cl})}
$$

Assuming that Brønsted's first postulate corresponds to the quotient term of Debye-Hückel's extended semi-empirical equation and that the second postulate corresponds to the linear term of the equation, the dependence of the $\mathrm{p} K$ value for acetic acid on the concentration of potassium chloride can be represented by the following equation:

where

$$
\mathrm{p} K_{\mathrm{KCl}}=\mathrm{p} K_{\mathrm{o}}-\frac{\mathrm{A}^{\prime} V \overline{I_{-}}}{1+\alpha_{\mathrm{H}(-))} \sqrt{I_{-}}}-\frac{\mathrm{A}^{\prime} V \overline{I_{+}}}{1+\alpha_{\mathrm{Ac}(+)} V \overline{I_{+}}}+\mathrm{BI},
$$

$$
\begin{gathered}
\frac{\mathrm{A}^{\prime} V \overline{I_{-}}}{1+\alpha_{(\mathrm{H}-)} V \overline{I_{-}}}=\mathrm{p} f_{\mathrm{H}(\mathrm{Cl})}+\mathrm{p} f_{\mathrm{H}(\mathrm{K})} \\
\frac{\mathrm{A}^{\prime} V \overline{I_{+}}}{1+\alpha_{\mathrm{Ac}(+)} V \overline{I_{+}}}=\mathrm{p} f_{\mathrm{Ac}(\mathrm{K})}+\mathrm{p} f_{\mathrm{Ac}(\mathrm{Cl})} \\
\mathrm{B} I=\mathrm{p} f_{(\mathrm{K})}+\mathrm{p} f_{(\mathrm{Cl})}
\end{gathered}
$$

In the equations, $I_{+}$represents the strength of the positive ions and $I_{-}$ that of the negative ions. They are defined as $I_{+}=\Sigma z_{+}^{2} c_{+}$and $I_{-}=\Sigma \mathrm{z}_{-}^{2} c_{-}$, where $z$ and $c$ are the charge and the concentration of the ions concerned; $I$ has its old designation. This was deduced from the assumption that according to Bronsted's theory $\mathrm{p} f_{\mathrm{H}(\mathrm{K})}=\mathrm{p} f_{\mathrm{Ac}(\mathrm{Cl})}$, and thus they have no specific properties. For this reason only ions of opposite charge give specific properties to equations (14) and (15), their ionic strength also being crucial. For the same reason the $\alpha$ parameter is given a designation which indicates what specific interaction between the ions is referred to.

In the following a method for evaluating these parameters is presented. This seems to give at least approximately reliable results and it lends support to the ideas presented. It differs from the method of calculation proposed earlier by the writer ${ }^{13}$, which later proved to be incorrect.

Debye-Hückel's equation expressing the negative logarithm of the activity coefficient of, for instance, hydrochloric acid is written as a function of the ionic strength in a form corresponding to equation (13),

$$
\mathrm{p} f_{\mathrm{HC}(\mathrm{HC})}=-\frac{\mathrm{A}^{\prime} \sqrt{I_{+}}}{1+\alpha_{\mathrm{Cl}(\mathrm{H})} V \overline{I_{+}}}-\frac{\mathrm{A}^{\prime} V \overline{I_{-}}}{1+\alpha_{\mathrm{H}(\mathrm{Cl})} \sqrt{I_{-}}}+\mathrm{B} I+\mathrm{D} I^{2}
$$


The method of calculation is based on the plausible assumption that $\alpha_{\mathrm{Cl}(\mathrm{H})}=\alpha_{\mathrm{H}(\mathrm{Cl})}$. Since $f_{\mathrm{Cl}(\mathrm{Cl})}=f_{\mathrm{H}(\mathrm{H})}$, it follows that $f_{\mathrm{Cl}(\mathrm{H})} f_{\mathrm{Cl}(\mathrm{Cl})}=f_{\mathrm{H}(\mathrm{Cl})} f_{\mathrm{H}(\mathrm{H})}$. The same assumption is naturally valid for all solutions of single electrolytes. Where these are concerned, the quotient term of equation (17) can be combined into one, leaving three unknowns in the equation, which can be solved if at least three points on the curve are known.

Even if the $\alpha$ parameters concerned were of different magnitude, the quotient terms could be combined without involving any great error. The $\alpha$ parameter of the combined quotient term is approximately the mean value of the $\alpha$ parameters of the original quotient terms, because the graph of the equation obtained is similar to the original one within the limits of experimental error ${ }^{13}$. This is the case when a mixture of two electrolytes is examined. If equation (17) is used to represent the dependence of the mean activity coefficient of hydrochloric acid on the concentration of potassium chloride the $\alpha$ parameters will be $\alpha_{\mathrm{H}(\mathrm{Cl})}$ and $\alpha_{\mathrm{Cl}(\mathrm{K})}$, which are not equal. When the quotient terms are combined, the value of the parameter becomes approximately

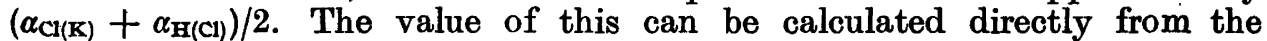
experimental data. On the other hand, $\alpha_{\mathrm{H}(\mathrm{Cl})}$ and $\alpha_{\mathrm{Cl}(\mathrm{K})}$ can be obtained from the measurements which were performed with hydrochloric acid and potassium chloride. Inserting these values into equation (17), the sum of the quotient terms can be calculated and from this backwards the value of the $\alpha$ parameter of the combined quotient term, which should be the same as that obtained by direct calculations from the experimental data, if the assumption that $a_{+(-)}=\alpha_{-(+)}$and Brønsted's first postulate are valid.

Harned and Owen ${ }^{7 d}$ have calculated the values of Debye-Hückel's parameters for solutions of hydrochloric acid and hydrobromic acid and for the corresponding alkali salts. From Harned's ${ }^{6}$ and his co-workers' measurements, which deal with the mean activity coefficient of hydrochloric and hydrobromic acid in solutions of the corresponding alkali metal salts, the values of the corresponding parameters can be calculated. Harned and Hickey ${ }^{14}$ have studied the ionization of acetic acid in lithium, sodium and potassium chloride

Table 1.

\begin{tabular}{|c|c|c|c|c|c|}
\hline Solutions & $\alpha_{\text {obt. }}$ & $\alpha_{\text {calc }}$ & Solution & $\alpha_{\text {obt. }}$ & $\boldsymbol{\alpha}_{\text {calc. }}$ \\
\hline $\begin{array}{l}\mathrm{HCl}(\mathrm{HCl}) \\
\mathrm{NaCl}(\mathrm{NaCl}) \\
\mathrm{KCl}(\mathrm{KCl}) \\
\mathrm{CsCl}(\mathrm{CsCl}) \\
\mathrm{HCl}(\mathrm{NaCl}) \\
\mathrm{HCl}(\mathrm{KCl}) \\
\mathrm{HCl}(\mathrm{CsCl}) \\
\mathrm{NaCl}(\mathrm{HCl}) \\
\mathrm{KCl}(\mathrm{HCl}) \\
\mathrm{CsCl}(\mathrm{HCl})\end{array}$ & $\begin{array}{l}1.41 \\
1.38 \\
1.27 \\
0.82 \\
1.34 \\
1.28 \\
1.03 \\
1.39 \\
1.15 \\
1.05\end{array}$ & $\begin{array}{l}1.39 \\
1.33 \\
1.07 \\
1.39 \\
1.33 \\
1.07\end{array}$ & $\begin{array}{ll}\mathrm{HBr}(\mathrm{HBr}) \\
\mathrm{NaBr}(\mathrm{NaBr}) \\
\mathrm{KBr}(\mathrm{KBr}) \\
\mathrm{HBr}(\mathrm{NaBr}) \\
\text { HBr(KBr) } \\
\text { * HCl(HCl) } \\
\text { * } \mathrm{LiAc}(\mathrm{LiAc}) \\
\text { * } \mathrm{NaAc}(\mathrm{NaAc}) \\
\text { * } \mathrm{KAc}(\mathrm{KAc}) \\
\text { * HAc(LiCl) } \\
\text { * HAc(NaCl) } \\
\text { * } \mathrm{HAc}(\mathrm{KCl})\end{array}$ & $\begin{array}{l}1.45 \\
1.38 \\
1.27 \\
1.36 \\
1.38 \\
1.44 \\
1.35 \\
1.30 \\
1.44 \\
1.51 \\
1.40 \\
1.25\end{array}$ & $\begin{array}{l}1.41 \\
1.35 \\
.\end{array}$ \\
\hline
\end{tabular}

* Has not been converted into mole fractions.

Acta Chem. Scand. 8 (1954) No. 7 
solutions. Harned and Owen re report the mean activity coefficients of the corresponding acetates. The same calculation can also be made from these data. In the foregoing table the results are listed. In the third column are found the values of the $a$ parameters obtained for mixed solutions by means of the method of calculation presented above, utilizing the values of the $\alpha$ parameters for pure solutions. The values obtained and those calculated are in good agreement in all cases except for $\mathrm{KCl}(\mathrm{HCl}), \mathrm{HAc}(\mathrm{LiCl})$ and $\mathrm{HAc}(\mathrm{KCl})$.

If the value 1.41 is used for the parameter $\alpha_{H(C)}$, the corresponding values for the $\alpha$ parameter of acetic acid in all the cases investigated ${ }^{1}$ can be calculated The values are listed in Table 2.

$$
\begin{aligned}
& \text { Table } 2 . \\
& a_{\mathrm{Ac}(\mathrm{L}, i)}=1.08 \quad \alpha_{\mathrm{Ac}(\mathrm{Na})}=1.515 \quad a_{\mathrm{AC}(\mathrm{K})}=1.70 \\
& \begin{array}{llll}
\alpha_{\mathrm{H}}(\mathrm{Cl})=1.41 & \alpha_{\mathrm{H}(\mathrm{Br})}=1.29 & a_{\mathrm{H}}\left(\mathrm{ClO}_{4}\right)=1.59 & a_{\mathrm{H}\left(\mathrm{NO}_{2}\right)}=2.03
\end{array}
\end{aligned}
$$

When these values are compared to those in Table 1 we notice that the three first are in opposite order in respect of their size. This may be caused by the acetate ion.

Olson and Simonson ${ }^{15}$ have studied equilibria in which only ions of like sign take part. They noticed that in the cases investigated only those ions of the added electrolytes which were of the opposite charge to the ions of the system affected the equilibrium and the activity of the ions taking part in it. These experiments were performed in dilute solutions, in which the quotient term of Debye-Hückel's equation is the determining factor. Thus, Olson's and Simonson's observations are completely in agreement with those presented above. Kilpi and his co-workers ${ }^{16}$ investigated similar equilibria, but in more concentrated solutions. They studied the hydrolysis of carbonate and phosphate ions and found that Olson's and Simonson's observations also hold approximately for more concentrated solutions. In both systems, however, the influence of ions of like sign is also clearly noticeable. According to the investigators mentioned these differences are certainly of almost the same magnitude as the probable error, but since in both cases the order of the experimental data is the same with respect to the anion of the added electrolyte, the difference must, in writer's opinion, be real. This is also to be expected on the basis of Brønsted's original theory as well as on that of the modification suggested here.

\section{Measurements performed on mixed solutions of alkali metal salts}

By means of numerous measurements on mixed solutions of alkali metal salts it was found that at constant ionic strength, the $\mathrm{p} K$ is a linear function of the concentration of the components. Some of the measurements are illustrated in Fig. 2. The diameter of the circles representing the experimental data is $0.004 \mathrm{pK}$ units. A direct consequence of the linear relation is the additivity of $\mathrm{p} K$, since by mixing, for instance, sodium chloride and potassium bromide in equivalent proportions the same solution is obtained as by dissolving sodium bromide and potassium chloride in the same proportions. Thus both 
Fig. 2. $p K$ of acetic acid in some mixtures of 2.7 molar total concentration plotted gainst the composition $x$ of the solution.

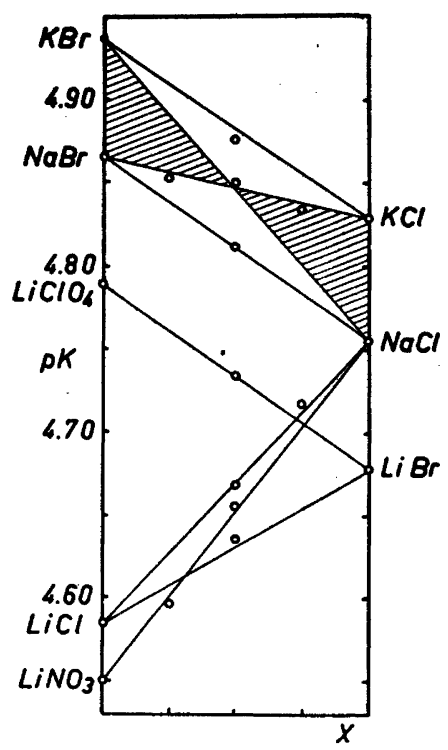

mixed systems have this point in common, and consequently two coincident triangles are formed, from which it further follows that $\mathrm{p} K_{\mathrm{KBr}}-\mathrm{p} K_{\mathrm{NaBr}}=$ $\mathrm{p} K_{\mathrm{KCl}}-\mathrm{p} K_{\mathrm{NaCl}}$.

\section{MEASUREMENTS PERFORMED ON SOLUTIONS OF SALTS OF ALKALINE EARTH METALS}

In view of the results obtained for solutions of alkali metal salts it seemed interesting to investigate the ionization of acetic acid in aqueous solutions of salts of the alkaline earth metals. It was assumed that in the case to be investigated the additivity should be valid just as for $1-1$ salts, and solutions were used in which the concentration of the anion was the same as in the solutions of the $1-1$ salts.

Comparison of the results with earlier measurements and Deb ye-H üc kel's parameters

The ionization of acetic acid in electrolytic solutions has been investigated by several investigators. Only Harned and Hickey ${ }^{17}$, and Larsson and Adell ${ }^{18}$ have, however, performed measurements on solutions of 2-1 salts, the former only on solutions of barium chloride, the latter both with barium and strontium chloride. In Table 3 the results of these investigators are compared with those of the present author.

Since the measurements were performed at two different ionic strengths and since the value of the thermodynamical ionization constant is known, the parameters of Debye-Hückel's equation can be evaluated. When the value 
Table 3. The $\mathrm{pK}$ of acetic acid in some 2-1 salt solutions according to various authors.

\begin{tabular}{|c|c|c|c|c|c|c|c|}
\hline \multicolumn{3}{|c|}{ Concentration in molalities } & \multicolumn{5}{|c|}{ Concentration in molarities } \\
\hline \multirow[b]{2}{*}{$I$} & \multicolumn{2}{|c|}{$\mathrm{BaCl}_{2}$} & \multirow[b]{2}{*}{$I$} & \multicolumn{2}{|c|}{$\mathrm{BaCl}_{2}$} & \multicolumn{2}{|c|}{$\mathrm{SrCl}_{2}$} \\
\hline & $\begin{array}{l}\text { Harned } \\
\text { Hickey }\end{array}$ & Ellilä & & $\begin{array}{c}\text { Larsson } \\
\text { Adell }\end{array}$ & Ellilä & $\begin{array}{c}\text { Larsson } \\
\text { Adell }\end{array}$ & Ellilä \\
\hline $\begin{array}{l}0.11 \\
0.51 \\
1.01 \\
2.01\end{array}$ & $\begin{array}{l}4.540 \\
4.442 \\
4.420 \\
4.434\end{array}$ & $\begin{array}{l}4.529 \\
4.418 \\
4.387 \\
4.386\end{array}$ & $\begin{array}{l}0.16 \\
0.76 \\
1.36 \\
.151\end{array}$ & $\begin{array}{l}4.516 \\
4.406 \\
4.391\end{array}$ & $\begin{array}{l}4.502 \\
4.397 \\
4.385 \\
-\end{array}$ & $\begin{array}{l}4.510 \\
4.385 \\
\overline{4.362}\end{array}$ & $\begin{array}{l}\mathbf{4 . 4 8 9} \\
\mathbf{4 . 3 7 1} \\
\overrightarrow{4.359}\end{array}$ \\
\hline & $\mathbf{4 . 4 3 4}$ & 4.386 & 3.01 & - & - & 4.414 & $\mathbf{4 . 4 1 7}$ \\
\hline
\end{tabular}

4.757, determined for $\mathrm{p} K_{\mathrm{o}}$ of acetic acid by Harned and Ehlers ${ }^{20}$ and by Kilpi and Meretoja ${ }^{19}$, is employed, the parameters obtain the values listed in Table 4.

Table 4. The $\alpha$ and $B$ parameters of the Debye-Hückel formula.

\begin{tabular}{|c|c|c|c|c|c|c|}
\hline Anion & \multicolumn{2}{|c|}{$\mathrm{Cl}$} & \multicolumn{3}{|c|}{$\mathrm{NO}_{3}$} & \multicolumn{2}{c|}{$\mathrm{ClO}_{4}$} \\
\cline { 2 - 7 } Cation & $\alpha$ & $\mathrm{B}$ & $\alpha$ & $\mathrm{B}$ & $a$ & $\mathrm{~B}$ \\
\hline $\mathrm{Ba}$ & $\mathbf{1 . 2 8 6}$ & $\mathbf{0 . 0 7 3 8}$ & & & $\mathbf{0 . 1 2 0 6}$ \\
$\mathrm{Sr}$ & $\mathbf{1 . 0 8 9}$ & $\mathbf{0 . 0 8 8 7}$ & 1.310 & $\mathbf{0 . 0 6 0 7}$ & $\mathbf{1 . 1 2 5}$ & $\mathbf{0 . 1 1 8 8}$ \\
$\mathrm{Ca}$ & $\mathbf{1 . 0 4 5}$ & $\mathbf{0 . 0 5 7 5}$ & $\mathbf{1 . 1 4 0}$ & $\mathbf{0 . 0 4 2 6}$ & $\mathbf{1 . 0 3 5}$ & $\mathbf{0 . 0 9 3 3}$ \\
\hline
\end{tabular}

The parameters in the table follow the expected sequences with respect to their magnitudes with the exception that in the chloride column the order of the B terms for strontium and calcium is improbable. According to the theory, $\mathrm{p} K$ values compared to mole fractions should have been used in the calculations of these parameters. This, however, was not done. Instead the values of the last column in Table 7 were used directly, as the aim was not to compare the values of the parameters with the theory but to facilitate an interpolation and extrapolation by means of them.

The additivity of the pKof aceticacid in solutions of $2-1$ s a l t s

In Table 5 the experimental results are listed as $\mathrm{p} K$ values. The differences of the values for different anions are also calculated.

In the fifth column of Table 5 the mean value of the differences is given. The error is ca. $\pm 0.004 \mathrm{p} K$ units when $I=1.5$. This is almost the same as for solutions of $1-1$ salts. When $I=4.05$ the error is ca. $\pm 0.008 \mathrm{p} K$ units, which is slightly smaller than that for $1-1$ salts. Thus, the additivity holds for 2-1 salts with approximately the same accuracy as for $1-1$ salts.

The accuracy of the measurements is insufficient to allow of a reliable comparison between the differences listed in Table 5 and those observed for the corresponding $1-1$ salts. For $1-1$ salts it is observed ${ }^{1}$ that if $I=1.0$, it follows that $\mathrm{p} K_{\mathrm{ClO}_{4}}-\mathrm{p} K_{\mathrm{Cl}}=0.084, \mathrm{p} K_{\mathrm{ClO}_{4}}-\mathrm{p} K_{\mathrm{NO}}=0.078$ and $\mathrm{p} K_{\mathrm{NO}}$ 
Table 5. Differences due to different anions between the $p K$ values of acetic acid measured in solutions of $2-1$ salts.

$I=1.5$

\begin{tabular}{|l|c|c|c|c|c|}
\hline Anion & $\mathrm{Ca}$ & $\mathrm{Sr}$ & $\mathrm{Ba}$ & $\begin{array}{c}\text { mean of } \\
\text { difference }\end{array}$ & $\begin{array}{c}2 / 3 \text { of diff. } \\
\text { of } 1-1 \text { salts }\end{array}$ \\
\hline $\mathrm{ClO}_{\mathrm{Cl}}$ & $\begin{array}{l}4.350 \\
4.300\end{array}$ & $\begin{array}{l}4.414 \\
4.359\end{array}$ & $\begin{array}{l}4.439 \\
4.386\end{array}$ & & \\
\hline diff. & $\mathbf{0 . 0 5 0}$ & 0.055 & 0.053 & 0.052 & 0.056 \\
\hline
\end{tabular}

\begin{tabular}{|c|c|c|c|c|c|}
\hline $\mathrm{ClO}_{4}$ & 4.350 & 4.414 & & & \\
$\mathrm{NO}_{3}$ & 4.304 & 4.377 & & & \\
\hline diff. & $\mathbf{0 . 0 4 6}$ & 0.037 & & $0.041(5)$ & 0.052 \\
\hline
\end{tabular}

\begin{tabular}{|l|l|l|l|l|l|}
\hline $\mathrm{NO}_{3}$ & 4.304 & 4.377 & & & \\
\hline diff. & 0.004 & 0.018 & & 0.011 & 0.004 \\
\hline
\end{tabular}

$I=4.05$

\begin{tabular}{|l|l|l|l|l|l|}
\hline $\mathrm{ClO}_{4}$ & 4.474 & 4.614 & 4.653 & & \\
$\mathrm{Cl}$ & 4.333 & 4.478 & 4.488 & & \\
\hline diff. & 0.141 & 0.136 & 0.165 & 0.147 & 0.136 \\
\hline
\end{tabular}

\begin{tabular}{|c|c|c|c|c|c|}
\hline $\mathrm{ClO}_{4}$ & 4.474 & 4.614 & & & \\
$\mathrm{NO}_{3}$ & 4.311 & 4.442 & & & \\
\hline diff. & 0.163 & 0.172 & & $0.167(5)$ & 0.163 \\
\hline
\end{tabular}

\begin{tabular}{|l|l|l|l|l|l|}
\hline $\mathrm{Cl}$ & 4.333 & 4.478 & & & \\
$\mathrm{NO}_{3}$ & 4.311 & 4.442 & & & \\
\hline diff. & 0.022 & 0.036 & & 0.029 & 0.027 \\
\hline
\end{tabular}

$-\mathrm{p} K_{\mathrm{Cl}}=0.006$. If $I=2.7$ we have correspondingly $0.202,0.244$ and 0.042 . These values multiplied by two thirds are appended in the sixth column of Table 5. Within the limits of experimental error it seems to be true that, if the concentration of the anion is the same, the differences in $\mathrm{p} K$ for the anions in solutions of 2-1 salts equal two thirds of the values which they have in solutions of $1-1$ salts. In the light of Brønsted's theory this means that the effect of the anion in a solution of a 2-1 salt is only two thirds of its effect in a solution of a 1-1 salt. Apparently the effect of the anion in a solution of a 3-1 salt would be only half of its effect in a solution of a $1-1$ salt, etc. This means that, depending on the properties of the dissolved salt that affect the $\mathrm{p} K$ value of acetic acid, the corresponding Debye-Hückel equation also attains different forms. For 2-1 salts equation (13) should be written as follows:

$$
\mathrm{p} K_{2-1}=\mathrm{p} K_{\mathrm{o}}-\frac{2 / 3 \mathrm{~A}^{\prime} \sqrt{I_{-}}}{1+\alpha_{\mathrm{H}(-)} \sqrt{I_{-}}}-\frac{4 / 3 \mathrm{~A}^{\prime} \sqrt{I_{+}}}{1+\alpha_{\mathrm{Ac}(+)} \sqrt{I_{+}}}+\mathrm{B} I
$$

Acta Chem. Scand. 8 (1954) No. 7 
and for 3-1 salts

$$
\mathrm{p} K_{8-1}=\mathrm{p} K_{\mathrm{o}}-\frac{1 / 2 \mathrm{~A}^{\prime} V \overline{I_{-}}}{1+\alpha_{\mathrm{B}(-)} V \overline{I_{-}}}-\frac{3 / 2 \mathrm{~A}^{\prime} \sqrt{I_{+}}}{1+\alpha_{\mathrm{Ad}+)} V \overline{I_{+}}}+\mathrm{BI}
$$

It should be noted that the sum of the ratios which represent valence factors must equal two in order that the limiting slope of the combined equation may obtain a correct value which is in conformity with the experimental data. Consequently, if the effect of the anion in a solution of a 2-1 salt is two thirds of its effect in a solution of a $1-1$ salt, the effect of a bivalent cation on the anion of acetic acid must be correspondingly greater than that of an equivalent quantity of univalent cation. For this reason the coefficient must be equal to $4 / 3$.

\section{MEASUREMENTS ON MIXED SOLUTIONS OF 2-1 AND 1-1 SALTS}

In mixed solutions of $1-1$ salts it was observed that the $\mathrm{p} K$ of acetic acid at constant ionic strength was a linear function of the concentration of the components. With a few measurements it was found that the same is also true for mixed solutions of $2-1$ salts.

In investigations of mixtures of $2-1$ and $1-1$ salts it was found 21 that the logarithm of the mean activity coefficient increases or decreases linearly at constant ionic strength. Similar investigations were performed with acetic acid in mixed solutions of sodium chloride and barium chloride. In Fig. 3 the results of the measurements are illustrated. It is observed that the $p K$ increases almost linearly with the increase of the ionic strengths of the components. Each point in the figure represents the mean of two measurements. The mean of the differences between the parallels for six points is ca. $0.005 \mathrm{pK}$ units. The diameter of the circles which represent the results is $0.005 \mathrm{p} K$ units, which can be considered the probable error of the measurements. As all the points measured lie below the straight line between the limiting values, it is, however, to be considered probable that the relationship investigated is not completely linear, but that the $\mathrm{p} K$ is dependent on the ionic strengths of the components according to an equation of higher order. The deviation from the linear relation is not great, but apparently real. Randall and Breckenridge ${ }^{22}$ have made a similar observation at high concentration when they investigated the change of the mean activity coefficients of hydrochloric acid in solutions of barium chloride and hydrochloric acid at constant ionic strength.

Just as the concentration of the 2-1 salts was chosen so that the anion concentration was the same as that used for $1-1$ salts, a series of measurements was performed on a mixture where the anion concentration was constant. The salts in the solution were sodium perchlorate and barium perchlorate. The results are illustrated in Fig. 4. Two measurements were made in each of the two pure solutions and the mean values of these was taken as the actual result. On the other hand, in the mixtures only one measurement was made for each point. The diameter of the circles representing the experimental results is $0.005 \mathrm{p} K$ units, as in the former case. 


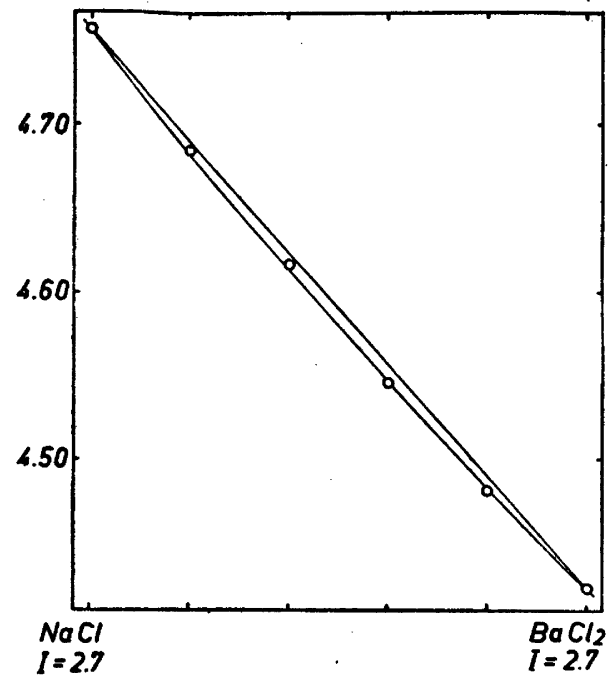

Fig. 3. $p K$ of acetic acid in mixtures of sodium chloride and barium chloride. Ionic strength 2.7. The circles represent the measurements. The curve has been calculated utilizing equation (23).

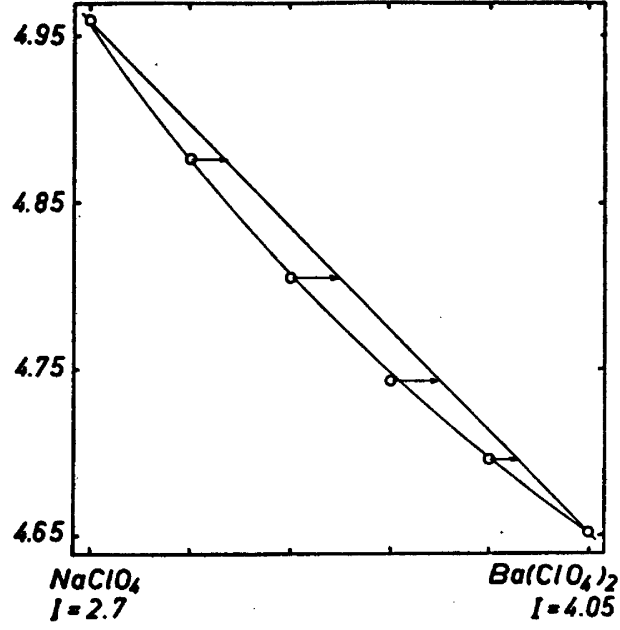

Fig. 4. $p K$ of acetic acid in mixtures of sodium perchlorate and barium perchlorate at constant anion concentration. The circles represent the measurements. The curve has been calculate utilizing equation (23).

Figure 4 shows clearly that the relationship between the $\mathrm{p} K$ and the composition of the mixture is of a higher order if the anion concentration is maintained unchanged. On the basis of the measurements concerning solutions of $1-1$ salts the conclusion was drawn that the cations and the anions of the electrolyte affect the equilibrium separately. Accordingly, the curvature of the graph should depend only on the difference in the effect of the univalent and bivalent cations. For a study of the effect of the equivalent ratios of these ions the cases in question are exceedingly interesting.

The study is best undertaken by attempting to find an equation which holds for the experimental data by suitable applications or corrections of Debye-Hückel's equation. The equation must consequently be built up of terms which have been obtained from measurements of both components in pure solutions. The most significant attempts are presented here:

1. The case is examined in the light of the concept of ionic strength. At each point of the curve (Fig. 4) the ionic strength is different. This fact must be taken into consideration and the values of the points should be calculated on this basis. The equation to be used in the calculations has the form

$$
\mathrm{p} K=\frac{I_{\mathrm{NaClO}_{4}}}{I} K_{\mathrm{NaClO}_{4}}+\frac{I_{\mathrm{Ba}\left(\mathrm{ClO}_{4}\right)_{2}}}{I} \mathrm{p} K_{\mathrm{Ba}\left(\mathrm{ClO}_{4}\right)_{2}}
$$

which represents a straight line.

Acte Chem. Scand. 8 (1954) No. 7 
2. The following equation leads to a good result:

$$
\mathrm{p} K=\frac{I_{\mathrm{NaClO}_{4}}}{I} \mathrm{p} K_{\mathrm{NaClO}_{4}, \mathrm{I}=2.7}+\frac{I_{\mathrm{Ba}\left(\mathrm{ClO}_{4}\right)_{2}}}{I} \mathrm{p} K_{\mathrm{Ba}\left(\mathrm{ClO}_{4}\right)_{2}, \mathrm{I}=5.4}
$$

Here, the ratio of the ionic strengths was used. Thus the measured points in the graph move through distances which are represented by the arrows. They then come to lie, within the accuracy of measurements, on the straight line that connects the limiting values. As regards the concept of ionic strength this calculation method is incorrect, since according to Debye-Hückel's theory the ionic strength of the solution to be investigated must be used. In equation (21) the ionic strengths of the limiting values are considered, whereas at the point examined the ionic strength has a value which lies between these values.

Equation (21) has, however, an interesting significance of its own. According to it the $\mathrm{p} K$ value is linearly dependent on the relation between the ionic strengths if the anion concentration is constant. For instance of sodium chloride and barium bromide the same solution is obtained as of sodium bromide and barium chloride when they are mixed in equivalent proportions. For this reason it follows directly from equation (21) that

$$
2 / 3\left(\mathrm{p} K_{\mathrm{NaBr}}-\mathrm{p} K_{\mathrm{NaCl}}\right)=\mathrm{p} K_{\mathrm{BaBr}_{2}}-\mathrm{p} K_{\mathrm{BaCl}_{\mathbf{s}}}
$$

This means that for the anions the difference between the values of $\mathrm{p} K$ is equal to $2 / 3$ of the correspoding differences in solutions of $1-1$ salts. This provides evidence in fayour of the observation mentioned in connection with Table 5.

3. For acetic acid in a solution of sodium perchlorate, equation (13) is valid. Likewise equation (18) is valid in a solution of barium perchlorate. When these equations are combined, an equation is obtained for the case illustrated in Fig. 4.

$$
\begin{aligned}
\mathrm{p} K=\mathrm{p} K_{\mathrm{o}}- & \frac{4 / 3 \mathrm{~A}^{\prime} \sqrt{I_{+}}}{1+\alpha_{\mathrm{Ac}(\mathrm{Ba})} \sqrt{I_{+}}}-\frac{\mathrm{A}^{\prime} V \overline{I_{+}}}{1+\alpha_{\mathrm{Ac}(\mathrm{Na})} V \overline{I_{+}}}-\frac{2 / 3 C_{\mathrm{Ba}}+1 / 2 C_{\mathrm{Na}}}{I_{-}} \\
& \frac{2 \mathrm{~A}^{\prime} \sqrt{I_{-}}}{1+\alpha_{\mathrm{H}\left(\mathrm{ClO}_{4}\right)} \sqrt{I_{-}}}+I_{\mathrm{NaClO}_{4} \mathrm{~B}_{\mathrm{NaClO}_{4}}+I_{\mathrm{Ba}\left(\mathrm{ClO}_{4}\right)_{2}} \mathrm{~B}_{\mathrm{Ba}\left(\mathrm{ClO}_{4}\right)_{2}}}
\end{aligned}
$$

This equation is derived on the assumption that the effect of the different ions is proportional to their ionic strength. If the observations and the conclusions drawn from them are correct, then equation (23) should correspond to the measurements illustrated in Figs. 3 and 4. Before this the values of the corresponding $\alpha$ parameters must be calculated. These can be calculated by the insertion in equation (18) of 1.59 from Table 2 in place of $\alpha_{H\left(\mathrm{ClO}_{4}\right)}$ and correspondingly from Tables 4 and 5 the values of $\mathrm{p} K$ and $I_{\left.\mathrm{Ba}_{(\mathrm{ClO})}\right) \cdot \text { If } I=}$ 4.05, the result is $\alpha_{\mathrm{Ac}(\mathrm{Ba})}=1.10$. Inserting these values and 0.2481 for $\mathrm{B}_{\mathrm{NaClO}_{4}}{ }^{1}$ and 1.515 for $\alpha_{\mathrm{Ac}(\mathrm{Na})}{ }^{1}$ into equation (23), the curve in Fig. 4 is obtained. The agreement between the calculated and observed values is good, as the mean value of their differences is $0.0035 \mathrm{pK}$ units.

Correspondingly the case illustrated in Fig. 3 can be calculatea. As the experiments do not yield the ideal results displaying additivity, the correspond- 
ing $\alpha$ parmaeters do not have constant values either. For this reason in the case in question the value of $\alpha_{\mathrm{Ac}(\mathrm{Ba})}$ must be calculated again. The result is 1.27. Utilizing this and 0.1813 for $B_{\mathrm{Nacl}^{1}}$ values are obtained which are represented by the curve in Fig. 3. The agreement is good again. The corresponding case observed by Randall and Breakenridge, which was mentioned earlier, can apparently be explained on the same basis.

\section{The $\alpha$ parameters formultivalent ions}

In Table 1 it has been shown that the assunptions that $\alpha_{+(-)}=\alpha_{-(+)}$and that the $\alpha$ parameter is a function of the sum of the ionic radii of two interacting ions of unlike sign are not in disagreement with the experimental data for 1-1 salts and acids. A similar investigation may be made for ions of higher valences. For this purpose the equation representing the dependence of the activity coefficient of $2-1$ salts on their concentrations is written in the following form:

$$
\mathrm{p} f=\frac{10 / 3 \mathrm{~A}^{\prime} V \overline{I_{-}}}{1+\alpha_{+(-)} \sqrt{I_{-}}}+\frac{8 / 3 \mathrm{~A}^{\prime} V \overline{I_{+}}}{1+\alpha_{-(+)} \sqrt{I_{+}}}-\mathrm{B} I-\mathrm{D} I^{2}
$$

It should be noted concerning the valence factors in the equation that the activity coefficient for barium chloride, for instance, is in the form $f_{\mathrm{Ba}} \cdot f_{\mathrm{Cl}}$. Earlier it was found (eq. (18)) that univalent ions, on which bivalent ions act, have a valence factor equal to $4 / 3$. Since in this case there are two of them, we have 8/3. On the other hand, according to Debye-Hückel the value of

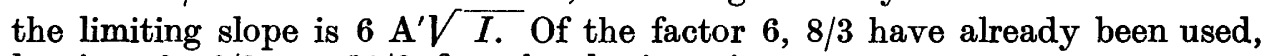
leaving $6-8 / 3=10 / 3$ for the barium ion.

The dependence of the mean activity coefficient of hydrochloric acid on this factor is expressed by equation (18), to which for the sake of conformity a second-order term $\mathrm{DI} I^{2}$ is to be added. Robinson ${ }^{23}$ has measured the mean activity coefficient for strontium chloride at different concentrations, whereas Vance ${ }^{24}$ has determined the mean activity coefficient of hydrochloric acid in solutions of strontium chloride. When $\alpha_{\mathrm{H}(\mathrm{Cl})}=1.4 \mathrm{l}$ is inserted into the earlier mentioned equation (18), which represents the dependence of the mean activity coefficient of hydrochloric acid on the concentration of strontium chloride, and when the parameter $\alpha_{\mathrm{cl}(\mathrm{Sr})}$ is calculated, the result is 1.61. When this value in turn is inserted into equation (24) and the parameter $\alpha_{+(-)}$is evaluated, we have $\alpha_{+(-)}=1.12$, which should be equal to $\alpha_{\mathrm{cl}(\mathrm{Sr})}$. The agreement is not good. Harned and Geary ${ }^{25}$ have determined the mean activity coefficient of hydrochloric acid in solutions of barium chloride, and Robinson ${ }^{23}$ that of barium chloride. If their experimental data are treated in the above way, the result is also unsatisfactory.

The dependence of the activity coefficient of $3-1$ salts on concentration is expressed by equation

$$
\mathrm{p} f=\frac{9 / 2 \mathrm{~A}^{\prime} \sqrt{I_{+}}}{1+\alpha_{-(+)} \sqrt{I_{+}}}+\frac{15 / 2 \mathrm{~A}^{\prime} V \overline{I_{-}}}{1+\alpha_{+(-)} \sqrt{I_{-}}}-\mathrm{B} I-\mathrm{D} I^{2}
$$


Correspondingly equation (19) represents the activity coefficient of hydrochloric acid in a solution of a 3-1 salt.

Robinson has corrected the values of the mean activity coefficient of cerium chloride obtained by Mason ${ }^{7 f}$. When the $\alpha$ parameters calculated from these values and from those of Mason and Kellam ${ }^{26}$ for hydrochloric acid in a solution of cerium chloride are compared in the manner described above, it is found that even in this case the agreement is not satisfactory.

These deviations may partly depend on the inaccuracy of the measurements but apparently other factors are also involved. The limiting slopes of the equations deviate somewhat from the original values of Debye-Hückel. For instance, in normal solutions of $2-1$ salts

$$
\begin{aligned}
4 / 3 \mathrm{~A}^{\prime} \sqrt{I_{+}}+2 / 3 \mathrm{~A}^{\prime} \sqrt{I_{-}} & =2.552 \mathrm{~A}^{\prime} \\
2 \mathrm{~A}^{\prime} \sqrt{I} & =2.450 \mathrm{~A}^{\prime}
\end{aligned}
$$

and

$$
\begin{aligned}
8 / 3 \mathrm{~A}^{\prime} \sqrt{I_{+}+10 / 3} \mathrm{~A}^{\prime} \sqrt{I_{-}} & =7.103 \mathrm{~A}^{\prime} \\
6 \mathrm{~A}^{\prime} & \sqrt{I}=7.350 \mathrm{~A}^{\prime}
\end{aligned}
$$

If in the value of $\mathbf{A}^{\prime}$ a correction corresponding to the difference is made, the result is no better. A great number of cases are, however, known in which the limiting slope does not completely correspond to the theoretical one, for which reason it is difficult to judge this effect. On the other hand, it should further be noted that the curves represented by the equations are not of entirely the same form as those represented by Debye-Hückel's original equation. The difference is not great, but at small ionic strengths, used in order to give the same results, the $\alpha$ parameters have values which differ considerably from each other. For instance, in a $\theta .01 \mathrm{M}$ solution of a $2-1$ salt the following requirement is set for the quotient term of a $1-1$ salt, if it is assumed that $\alpha_{-(+)}=\alpha_{+(-)}=1$.

$$
\frac{4 / 3 \mathrm{~A}^{\prime} \sqrt{0.04}}{1+1 \sqrt{0.04}}+\frac{2 / 3 \mathrm{~A}^{\prime} \sqrt{0.02}}{1+1 \sqrt{0.02}}=\frac{2 \mathrm{~A}^{\prime} \sqrt{0.03}}{1+0.8 \sqrt{0.03}}
$$

whereas for a 1 molar solution the requirements are as follows:

$$
\frac{4 / 3 \mathrm{~A}^{\prime} \sqrt{4}}{1+1 \sqrt{4}}+\frac{2 / 3 \mathrm{~A}^{\prime} \sqrt{2}}{1+1 \sqrt{2}}=\frac{2 \mathrm{~A}^{\prime} \sqrt{3}}{1+0.99 \sqrt{3}}
$$

Thus, for ionic strengths the equations become identical with Debye-Hückel's equation. This again indicates that the values of the $a$ parameters should be written as functions of the concentration, their value being greater at low concentrations than at high concentrations. Taking these facts into consideration, it is difficult to determine the validity or non-validity of the theory for multivalent ions on the basis of these calculations.

If, however, the calculations are treated in the way suggested in connection with Table 1, we obtain the results summarized in Table 6. 
Table 6.

\begin{tabular}{|c|c|c|c|c|c|}
\hline * Solution & $\alpha_{\text {obt. }}$ & $a_{\text {calc. }}$ & Solution & $a_{\text {obt. }}$ & $\alpha_{\text {calc. }}$ \\
\hline $\begin{array}{l}\mathrm{HCl}(\mathrm{HCl}) \\
\mathrm{BaCl}\left(\mathrm{BaCl}_{2}\right) \\
\mathrm{HCl}\left(\mathrm{BaCl}_{2}\right)\end{array}$ & $\begin{array}{l}1.44 \\
1.31 \\
1.42\end{array}$ & 1.38 & $\begin{array}{l}\mathrm{HCl}(\mathrm{HCl}) \\
\mathrm{SrCl}_{2}\left(\mathrm{SrCl}_{2}\right) \\
\mathrm{HCl}\left(\mathrm{SrCl}_{2}\right)\end{array}$ & $\begin{array}{l}1.41 \\
1.50 \\
1.51\end{array}$ & 1.46 \\
\hline
\end{tabular}

* Has not been converted into mole fractions.

It was earlier mentioned that Olson and Simonson have investigated the hydrolysis of the ferric ion. In this case the equilibrium may be expressed according to the law of mass action as $\left[\mathrm{FeOH}^{++}\right]\left[\mathrm{H}^{+}\right] /\left[\mathrm{Fe}^{+++}\right]=K$. According to Debye-Hückel's theory, the limiting slope should obtain the value $-4 \mathrm{~A}^{\prime} \sqrt{ } I$. The investigators mentioned observed, however, that the value of the limiting slope remained unchanged independent of the charge on the cation of the electrolyte added. Thus, in this case the limiting slope can be written in the form $-4 \mathrm{~A}^{\prime} \sqrt{I_{-}}$. If the ideas presented are applied to this case, the values of the limiting slopes are as follows:

$$
\begin{array}{ll}
\text { Salt } & (1+4-9) \mathrm{A}^{\prime} \sqrt{I_{-}}=-4 \mathrm{~A}^{\prime} \sqrt{I_{-}} \\
1-1 & (2 / 3+10 / 3-8) \mathrm{A}^{\prime} V \overline{I_{-}}=-4 \mathrm{~A}^{\prime} \sqrt{I_{-}} \\
2-1 & (1 / 2+3-15 / 2) \mathrm{A}^{\prime} \sqrt{I_{-}}=-4 \mathrm{~A}^{\prime} \sqrt{I_{-}}
\end{array}
$$

The terms 1, 4 and 9 in the sum at the left of the first equation follow directly from Debye-Hückel's theory. $2 / 3$ and $10 / 3$ are obtained from equation (18) and (24), and $1 / 2$ and $15 / 2$ from equations (19) and (25). 8 can be derived by considering that the ferric ion and the anion of the added salt, which is affected by the bivalent cation of this salt, act upon each other. The activity coefficient of this couple is consequently $f_{\mathrm{Fe}^{+++}} \cdot f_{-}^{3}$ and the corresponding valencee factor according to Debye-Hückel $9+3=12$. As, however, the amount of anions of the added salt is large in comparison to the amount of ferric ions, the former is the deciding factor. Since it is affected by a bivalent anion, its valence factor is $4 / 3$, leaving $12-3 \times 4 / 3=8$ for the ferric ion. The valence factor of the $\mathrm{FeOH}^{++}$ion can be calculated according to the same principle, yielding $6-2 \times 3 / 2=3$.

In the same way the values of the limiting slopes corresponding to equilibria investigated by Kilpi and his co-workers could be calculated, whereby it should be noted that they also have obtained values which differ from DebyeHückel's limiting slopes. . The equilibria investigated by them do not, however, make it possible to control this matter experimentally, because according to Kilpi ${ }^{27}$ the titrability vanishes in so dilute solutions as should be used in the investigation.

\section{EXPERIMENTAL}

The investigation was carr ed out at $25^{\circ} \mathrm{C}$ according to a method based on potentiometric titration and developed by Kilpi ${ }^{28}$. As electrode a quinhydrone electrode was mostly used. The accuracy of the potentiometer readings was $0.01 \mathrm{mV}$, which corresponds 
Table 7. Experimental results obtained in aqueous solutions of $2-1$ salts at $25^{\circ}$.

\begin{tabular}{|c|c|c|c|c|}
\hline Electrolyte & $I$ & $P \cdot 10^{8}$ & $\mathrm{p} K$ & $\mathrm{p} K_{\text {mean }}$ \\
\hline \multirow[t]{3}{*}{$\mathrm{CaCl}_{2}$} & 1.5 & $\begin{array}{l}6.320 \\
6.320\end{array}$ & $\begin{array}{l}4.300 \\
4.300\end{array}$ & 4.300 \\
\hline & 4.05 & $\begin{array}{l}6.115 \\
6.105\end{array}$ & $\begin{array}{l}\mathbf{4 . 3 3 0} \\
\mathbf{4 . 3 3 2}\end{array}$ & 4.333 \\
\hline & & 6.070 & 4.336 & \\
\hline \multirow[t]{2}{*}{$\mathrm{Ca}\left(\mathrm{NO}_{3}\right)_{2}$} & 1.5 & $\begin{array}{l}6.320 \\
6.255 \\
6.310\end{array}$ & $\begin{array}{l}4.300 \\
4.309 \\
4.302\end{array}$ & 4.304 \\
\hline & 4.05 & $\begin{array}{l}6.310 \\
6.275 \\
6.255 \\
6.200\end{array}$ & $\begin{array}{l}4.302 \\
4.307 \\
4.309 \\
4.317\end{array}$ & 4.311 \\
\hline \multirow[t]{2}{*}{$\mathrm{Ca}\left(\mathrm{ClO}_{4}\right)_{2}$} & 1.5 & $\begin{array}{l}6.000 \\
5.970\end{array}$ & $\begin{array}{l}4.348 \\
4.352\end{array}$ & 4.350 \\
\hline & 4.05 & $\begin{array}{l}5.220 \\
5.205\end{array}$ & $\begin{array}{l}4.472 \\
4.475\end{array}$ & 4.473 \\
\hline \multirow[t]{2}{*}{$\mathrm{SrCl}_{2}$} & 1.5 & $\begin{array}{l}5.890 \\
5.935 \\
5.935\end{array}$ & $\begin{array}{l}4.364 \\
\mathbf{4 . 3 5 7} \\
\mathbf{4 . 3 5 7}\end{array}$ & 4.359 \\
\hline & 4.05 & $\begin{array}{l}5.185 \\
5.195\end{array}$ & $\begin{array}{l}4.478 \\
4.477\end{array}$ & 4.477 \\
\hline \multirow[t]{2}{*}{$\mathrm{Sr}\left(\mathrm{NO}_{3}\right)_{2}$} & 1.5 & $\begin{array}{l}5.770 \\
5.835\end{array}$ & $\begin{array}{l}4.382 \\
4.372\end{array}$ & 4.377 \\
\hline & 4.05 & $\begin{array}{l}5.405 \\
5.400\end{array}$ & $\begin{array}{l}4.441 \\
4.442\end{array}$ & 4.442 \\
\hline $\mathrm{Sr}\left(\mathrm{ClO}_{4}\right)_{2}$ & $\begin{array}{l}1.5 \\
4.05\end{array}$ & $\begin{array}{l}5.565 \\
4.465 \\
4.445\end{array}$ & $\begin{array}{l}4.414 \\
4.612 \\
4.616\end{array}$ & $\begin{array}{l}4.414 \\
4.614\end{array}$ \\
\hline \multirow[t]{2}{*}{$\mathrm{Ba}\left(\mathrm{ClO}_{4}\right)_{2}$} & 1.5 & $\begin{array}{l}5.430 \\
5.405\end{array}$ & $\begin{array}{l}4.437 \\
4.441\end{array}$ & 4.439 \\
\hline & 4.05 & $\begin{array}{l}4.265 \\
4.260\end{array}$ & $\begin{array}{l}4.652 \\
4.653\end{array}$ & 4.652 \\
\hline \multirow[t]{2}{*}{$\mathrm{BaCl}_{2}$} & 1.0 & $\begin{array}{l}5.730 \\
5.750\end{array}$ & $\begin{array}{l}4.389 \\
4.385\end{array}$ & 4.387 \\
\hline & 2.7 & $\begin{array}{l}5.525 \\
5.515\end{array}$ & $\begin{array}{l}4.003 \\
4.422 \\
4.423\end{array}$ & 4.422 \\
\hline
\end{tabular}

to the accuracy with which the hydroxide can be added during the titration. For the addition of the latter a micro syringe, designed and constructed by the writer, was used, the accuracy being $\pm 0.1 \%$ for addition of $c a .0 .1 \mathrm{ml}$.

In Table 7 only those measurements are listed which were carried out in solutions of salts of alkaline earth metals, because the results of the measurements relating to solutions of alkali salts have been presented earlier. The solutions of the salts of alkaline earth metals were prepared by dissolving a weighed quantity of carbonate in the acid and diluting in a volumetric flask to the proper volume. In the first column of Table 7 is the electrolyte, in the second the concentration of the salt, expressed as ionic strength at the startingpoint of the titration. This is $c a .0 .2 \%$ higher than that at the inflexion point of the titration curve from which the ionization constant is calculated. In the third column is the buffer capacity, in the fourth the correesponding $\mathrm{p} K$ value and in the fifth the mean value of the $\mathrm{p} K$ values of parallel measurements. In all cases the concentration of acetic acid at the point of inflexion is 0.04044 . The ionization constant was not extrapolated to zero concentration of acetic acid. 


\section{SUMMARY}

The object of the investigation here reported was to study the ionization of acetic acid in colutions of $1-1$ and $2-1$ salts and in mixtures of these. Of the salts investigated, 11 were $1-1$ salts and 8 were $2-1$ salts. The temperature was in all cases $25^{\circ} \mathrm{C}$.

The results obtained may be summarized as follows:

1. It was found that the value of $\mathrm{p} K$ for acetic acid in solutions of $1-1$ salts is an additive quantity dependent separately on each species of ion in the solution.

2. This observation is compared to Brønsted's theory and the confirmity is found to be good.

3. Brønsted's theory is examined in the light of the results of other investigators and a correction made in the second postulate, the modified theory being applicable to concentrated solutions also.

4. Brønsted's theory and Debye-Hückel's equation are compared and a method is suggested for the calculation of the $\alpha$ parameter, which is dependent on the sum of the radii of the two interacting ions. This method seems to be at least approximately valid within the scope of the data presented.

5. The value of $\mathrm{p} K$ for acetic acid at constant ionic strength was found to be a linear function of the concentration of the components of the mixture. From this the additivity phenomenon follows directly.

6. Measurements on solutions of 2-1 salts indicated that in these solutions also the additivity phenomenon occurs.

7. In solutions of $2-1$ salts it appears that the anion only exerts twothirds of its effect in a solution of a $1-1$ salt, if the anion concentration is the same as in the.solution of the $1-1$ salt. This observation is examined and generalised to include solutions of salts of still higher valences. The corresponding equations are derived from Debye-Hückel's equation.

8. The results obtained in mixtures of $1-1$ and 2-1 salts are discussed. If the ionic strength is constant, $\mathrm{p} K$ in an almost linear function of the ionic strengths of the components. When the anion concentration is kept constant, $\mathrm{p} K$ is a function of higher order of the concentrations of the components. The corresponding equations are derived.

9. Measurements in which the anion concentration was maintained constant indicate that from them also additivity follows and that the effect of the anions in a solution of a $2-1$ salt is $2 / 3$ of its effect in a solution of a $1-1$ salt.

10. The possibility of calculating the values of the $\alpha$ parameter, which is dependent on the sum of the radii of the interacting ions, for ions of higher valences also, is examined.

11. It is concluded that, on the basis of the suggestions presented here, it is possible to explain some observed deviations from Debye-Hückel's limiting slope.

Miss A-L. Mukula, fil. mag., who made a part of the experimental work, is gratefully acknewledged.

Acta Chem. Scand. 8 (1954) No. 7 


\section{REFERENCES}

1. Ellilä, A. Ann. Acad. Sci. Fennicae. Ser. A. 11 (1953) No. 51.

2. Brønsted, J. N. J. Am. Chem. Soc. 42 (1920) 761; 44 (1922) 877; 44 (1922) 938; 45 (1923) 2898.

3. Bernsted, J. N. J. Am. Chem. Soc. 44 (1922) 881.

4. Larsson, E. Z. physik. Chem. (A) 153 (1931) 299.

5. Sugden, J. N. J. Chem. Soc. 128 (1926) 174.

6. Harned, H. S. J. Am. Chem. Soc. 37 (1938) 1865.

7. Harned, H. S. and Owen, B. B. The Physical Chemistry of Electrolytic Solutions, Reinhold Publishing Co. New York 1950: a) pp. 397 and 465, b) pp. 397-405, c) pp. 461-466, d) p. 381 , e) p. 563, f) p. 573.

8. Kortüm, G. Elektrolytlösungen, Akademische Verlagsgesellschaft Becker \& Erler Kom.-Ges. Leipzig 1941, p. 304.

9. Randall, M. and Failey, C. F. Chem. Revs. 4 (1927) 271.

10. Long, F. A. and McDevit, W. F. Chem. Revs. 51 (1952) 145.

11. Harned, H. S. and Hamer, W. J. J. Am. Chem. Soc. 55 (1933) 2194; Harned, H. S. and Mannweiler, G. E. Ibid. 57 (1935) 1873; Harned, H. S. and Copson, H. R. Ibid. 55 (1933) 2296; Harned, H. S. and Geary, C. G. Ibid. 59 (1937) 2032; Harned, H. S. and Hamer, W. J. Ibid. 55 (1933) 4496; Harned, H. S. and Donelson, J. G. Ibid. 59 (1937) 1280; Harned, H. S. and Schupp Jr. O. E. Ibid. 52 (1930) 3892.

12. Owen, B. B. and Cooke Jr, T. F. J. Am. Chem. Soc. 59 (1937) 2273.

13. Ellilä, A. Acta Chem. Scand. 6 (1952) 1562.

14. Harned, H. S. and Hickey, F. C. J. Am. Chem. Soc. 59 (1937) 1284.

15. Olson, A. R. and Simonson, T. R. J. Chem. Phys. 17 (1949) 348; 17 (1949) 1167; 17 (1949) 1322.

16. Kilpi, S., Mikkola, K. S., and Valanki, M. K. Ann. Acad. Sci. Fennicae. Ser. A. II (1953) No. 52.

17. Harned, H. S. and Hickey, F. C. J. Am. Chem. Soc. 59 (1937) 2303.

18. Larsson, E. and Adell, B. Z. physik. Chem. (A) 156 (1931) 365.

19. Harned, H. S. and Ehlers, R. W. J. Am. Chem. Soc. 54 (1932) 1350.

20. Kilpi, S. and Meretoja, A. Z. physik. Chem. (A) 179 (1937) 386.

21. Randall, M. and Breckenridge, G. F. J. Am. Chem. Soc. 49 (1927) 1435; Murdock, F. G. and Barton, R. C. Ibid. 55 (1933) 4074.

22. Randall, M. and Breckenridge, G. F. J. Am. Chem. Soc. 49 (1927) 1444.

23. Robinson, R. A. Trans. Faraday Soc. 36 (1940) 735.

24. Vance, J. E. J. Am. Chem. Soc. 55 (1933) 2729.

25. Harned, H. S. and Geary, C. G. J. Am. Chem. Soc. 59 (1937) 2032.

26. Mason, C. M. and Kellam, D. B. J. Phys. Chem. 38 (1934) 689.

27. Kilpi, S. Z. physik. Chem. (A) 173 (1935) 440.

28. Kilpi, S. J. Am. Chem. Soc. 74 (1952) 5296, and the literature cited there.

Received March 30, 1954. 